\title{
Analysis of dissipated energy and temperature fields at severe notches of AISI 304L stainless steel specimens
}

\author{
D. Rigon, M. Ricotta, G. Meneghetti \\ University of Padova, Department of Industrial Engineering, via Venezia 1 - 35131 Padova, Italy \\ daniele.rigon.1@phd.unipd.it, http:/ /orcid.org/0000-0003-0315-6628 \\ mauro.ricotta@unipd.it,http://orcid.org/0000-0002-4212-2618 \\ giovanni.meneghetti@unipd.it,bttp://orcid.org/0000-0002-3517-9464
}

ABSTRACT. In the last years, a large amount of fatigue test results from plain and bluntly notched specimens made of AISI 304L stainless steel were synthetized in a single scatter band by adopting the specific heat loss per cycle (Q) as a damage parameter. During a fatigue test, the Q parameter can be evaluated measuring the cooling gradient at a point of the specimens after having suddenly stopped the fatigue test. This measurement can be done by using thermocouples; however, due to the high stress concentration at the tip of severely notched components analysed in the present paper, an infrared camera achieving a much improved spatial resolution was adopted. A data processing technique is presented to investigate the heat energy distribution close to the notch tip of hot-rolled AISI 304L stainless steel specimens, having notch tip radii equal to 3,1 and $0.5 \mathrm{~mm}$ and subjected to constant amplitude cyclic loads. A thermal finite element analysis was also performed by assigning heat generation in the appropriate region close to the notch tip. Then the numerical temperature values were compared with the experimental measurement.

KEYWORDS. Energy Distribution; Fatigue; Notch Effect.

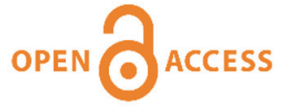

Citation: Rigon, D., Ricotta, M., Meneghetti, G., Analysis of dissipated energy and temperature fields at severe notches of AISI 304L stainless steel specimens, Frattura ed Integrità Strutturale, 47 (2018) 334-347.

Received: 01.11 .2018

Accepted: 03.12.2018

Published: 01.01.2019

Copyright: (C) 2019 This is an open access article under the terms of the CC-BY 4.0, which permits unrestricted use, distribution, and reproduction in any medium, provided the original author and source are credited.

\section{INTRODUCTION}

$\mathrm{F}$ atigue is an irreversible process, accompanied by microstructural changes, localized plastic strains and energy dissipation. The temperature increase of a metallic material undergoing a fatigue test is a manifestation of the thermal energy dissipation. Therefore, in the last decades; temperature has been used for the rapid estimation of fatigue limit in metallic materials and components [1-4], the detection and propagation of damage in metal materials and composites in [5-8] and the investigation of fatigue life under constant amplitude [9-11] and block loading [12,13]. Nevertheless, since temperature depends on the mechanical and thermal boundary conditions, the specific heat energy per cycle, Q, was assumed as a fatigue damage indicator in [14], because it is expected to be a material property, similarly to the plastic strain hysteresis energy $[15,16]$. 
a)

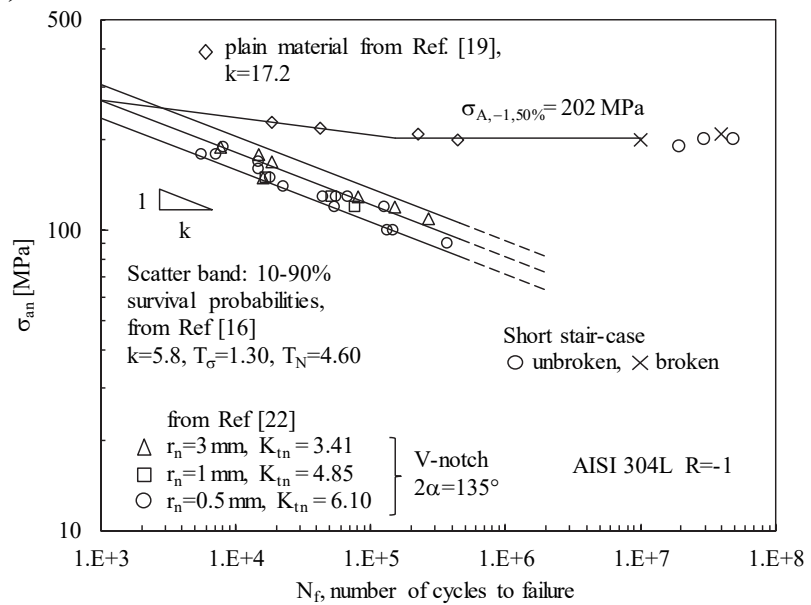

b)

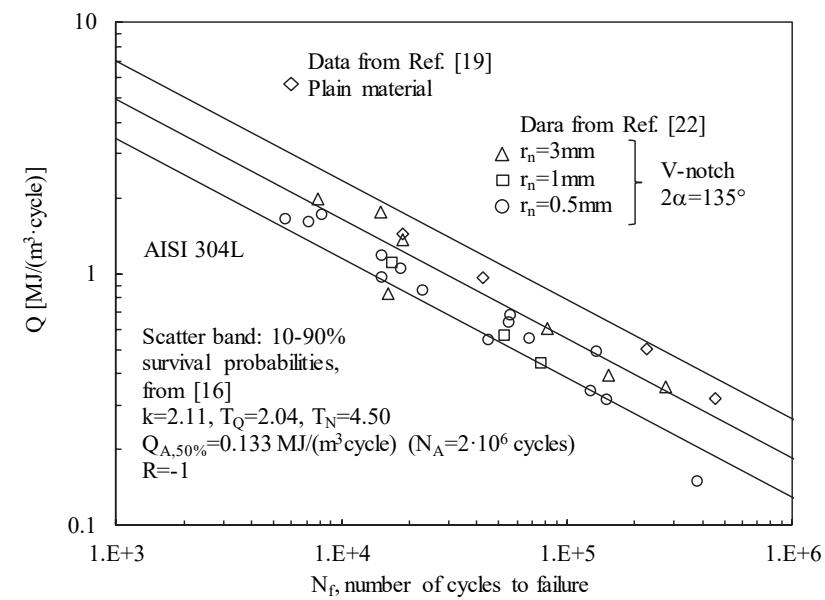

Figure 1: Fatigue test results of plain and notched AISI 304L in term of net-section stress amplitude (a) and re-elaborated in terms of specific heat loss Q (b). Data are extrapolated from Ref. [22].

In [14], a simple experimental technique was proposed to evaluate the $Q$ parameter at a point of a component, starting from the cooling gradient measured at that point immediately after the fatigue test has been stopped, according to Eqn. (1):

$$
Q=\frac{\rho \cdot c \cdot \partial T / \partial t}{f_{L}}
$$

where $T(t)$ is the time-variant temperature at the point, $\varrho$ is the material density, $c$ is the material specific heat and $f_{L}$ is the load test frequency.

a)

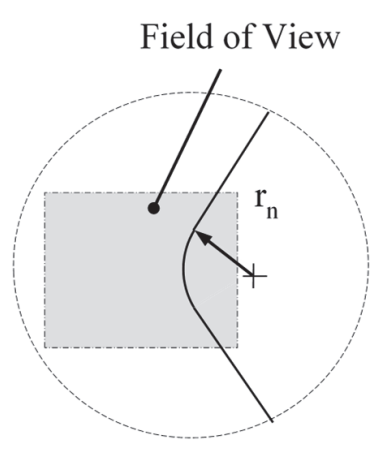

Machine grip

Machine grip

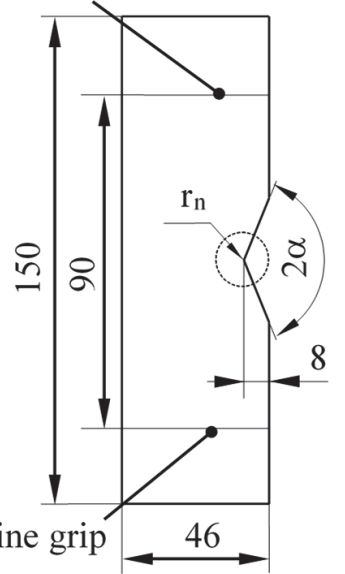

b)

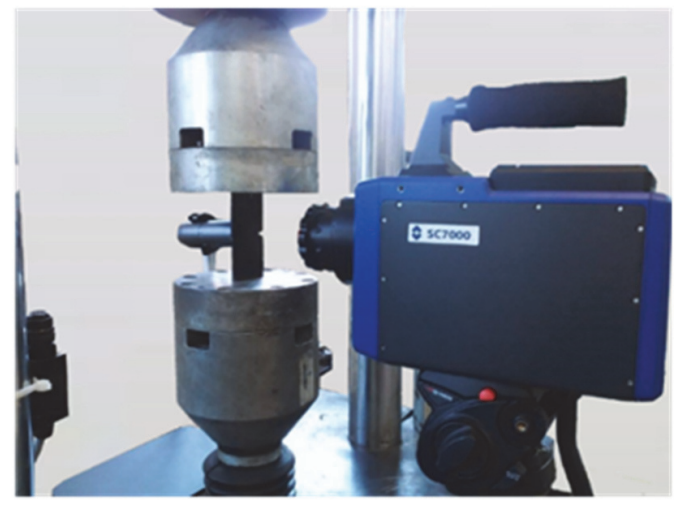

Figure 2: Specimen's geometry (a) and experimental setup of the fatigue tests carried out in Ref. [22] and analysed in the present contribution (b).

In [16-19], the Q parameter was adopted to synthesize 140 experimental results obtained from constant amplitude, pushpull, stress- or strain-controlled fatigue tests carried out on plain and notched hot rolled AISI 304L stainless steel specimens as well as from cold drawn un-notched bars of the same steel, under fully reversed axial or torsional fatigue loadings. The fatigue test results synthesized in term of $\mathrm{Q}$ fall in a single energy-based scatter band, which was fitted only on the fatigue test results relevant to plain material, hole specimens $\left(r_{n}=8 \mathrm{~mm}\right), \mathrm{U}\left(\mathrm{r}_{\mathrm{n}}=5 \mathrm{~mm}\right)$, and bluntly $\mathrm{V}\left(\mathrm{r}_{\mathrm{n}}=3 \mathrm{~mm}\right)$ notched specimens 
[16]. Depending on the severity of the stress concentration effect, the heat energy has been evaluated at a point or it has been averaged in a material volume. More precisely, in case of blunt notches, the specific heat loss has been evaluated at a point of a specimen (Q), i.e. at the notch tip; in case of severe V-notches or cracks, the specific heat loss has been averaged in a control volume of material surrounding the tip of the stress raiser $\left(Q^{*}\right)$ as proposed in $[20,21]$.

In $[16,18]$, thermocouples having wires of $0.127 \mathrm{~mm}$ in diameter were attached at the notch tip, by using $1.5-2 \mathrm{~mm}$ silverloaded glue dot diameter. Conversely, in [19,22] temperature was monitored by means of an infrared camera, because of the much more localized temperature field caused by the notch tip radii lower than $3 \mathrm{~mm}$, which had not been tested in [16,18].

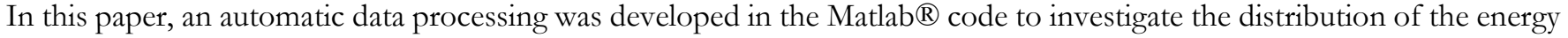
dissipated around the notch tip. Such a procedure was applied to the fatigue test results published in [22], which are synthesised in Fig. 1. Taking into account individual fatigue tests, a steady-state finite element analysis was performed assigning the distribution of specific heat power generation coming from the $\mathrm{Q}$ maps. Then, the numerical temperature results were compared to the experimental ones.

\section{MATERIALS AND METHODS}

\section{Experimental protocol}

pecimens characterised by three different notch tip radii $r_{n}$, namely 3,1 and $0.5 \mathrm{~mm}$, were machined from a 4-thick$\mathrm{mm}$ hot rolled AISI 304L stainless steel sheet, according to the geometry shown in Fig. 2a. The density and specific heat of the material are equal to $7940 \mathrm{~kg} / \mathrm{m}^{3}$ and $507 \mathrm{~J} /(\mathrm{kg} \mathrm{K})$, respectively.

A FLIR SC7600 infrared camera has been adopted for recording the T(x,y) temperature maps. In order to synchronize the force and temperature signals, the infrared camera was equipped with an analog input interface. In addition, a spacer ring was used to achieve a spatial resolution around $20 \mu \mathrm{m} /$ pixel. The frame dimension of 320x 256 pixels has been set and the notch was positioned in the center of the frame to exclude the temperature error caused by vignetting. To monitor the evolution of Q during each test, 1 to 10 temperature acquisitions (before crack initiation) were performed using a 10-secondlong sampling window with $\mathrm{f}_{\text {acq }}=200 \mathrm{~Hz}$ (2000 frames), starting from a time $\mathrm{t}_{\mathrm{s}}$. The time window consists of approximately 5 seconds of running test (i.e. 1000 frames between $t_{s}$ and $t^{*}$, Fig. 3a), followed by the machine stop at the time $t^{*}$, and the remaining 5 seconds of acquisition to capture the cooling gradient (i.e. additional 1000 frames after $\mathrm{t}^{*}$ ). With the aim to increase the material emissivity, one specimen's surface was black painted. On the contrary, the opposite surface was polished to detect the possible presence of a fatigue crack emanating from the notch tip, by using a AM4115ZT Dino-lite digital microscope (with a magnification ranging from 20x to 220x).

a)

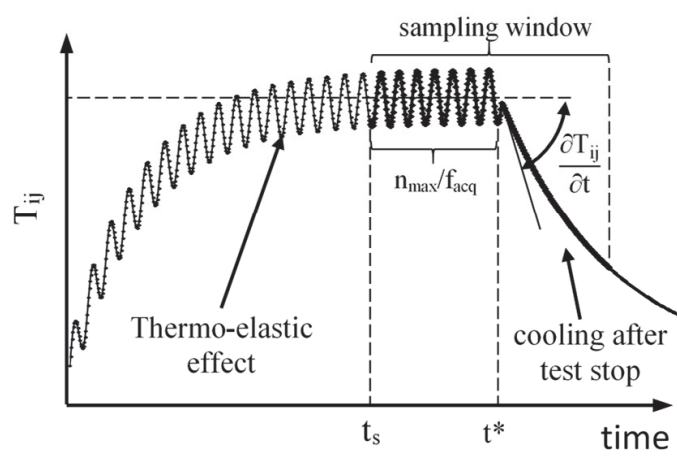

b)

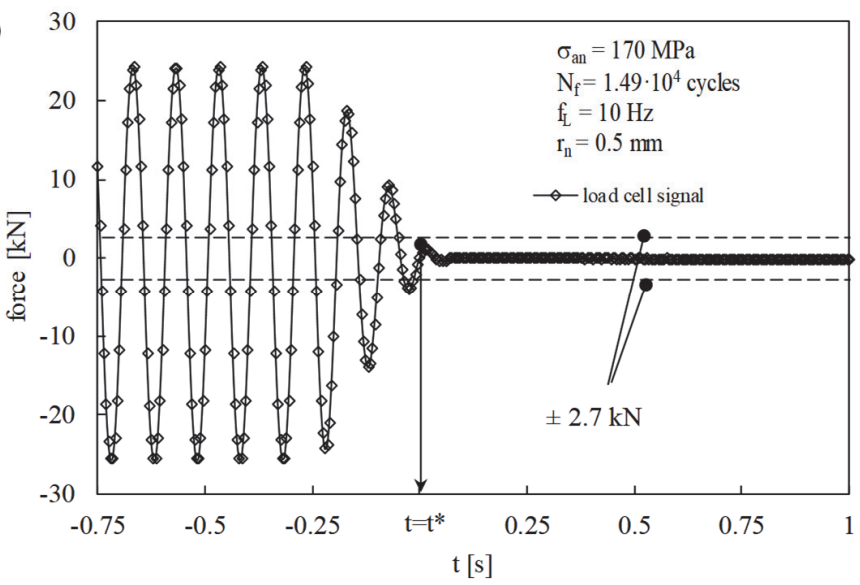

Figure 3: Schematic illustration of the time-variant temperature for one pixel (a) and an example of evaluation of the $t^{*}$ after a fatigue test stop. (b)

\section{Data post-processing}

The acquired temperature maps and force signal were post-processed by means of the ALTAIR 5.90.002 commercial software and saved as Altair PTW film file (*.ptw). Since the test machine takes some tenth of a second to definitively stop, an engineering definition of $t^{*}$ was introduced, as follows. The time $t^{*}$ was defined taking advantage of the data postprocessing carried out by using the ALTAIR 5.90.002 commercial software and it was defined as the time when the first 
peak of the tapered force amplitude signal is within the range of $\pm 2.7 \mathrm{kN}$, i.e. below $5 \%$ of the force amplitude relevant to the fatigue test in all the acquisitions. Fig. 3b reports an example of $\mathrm{t}^{*}$ evaluation.

a)

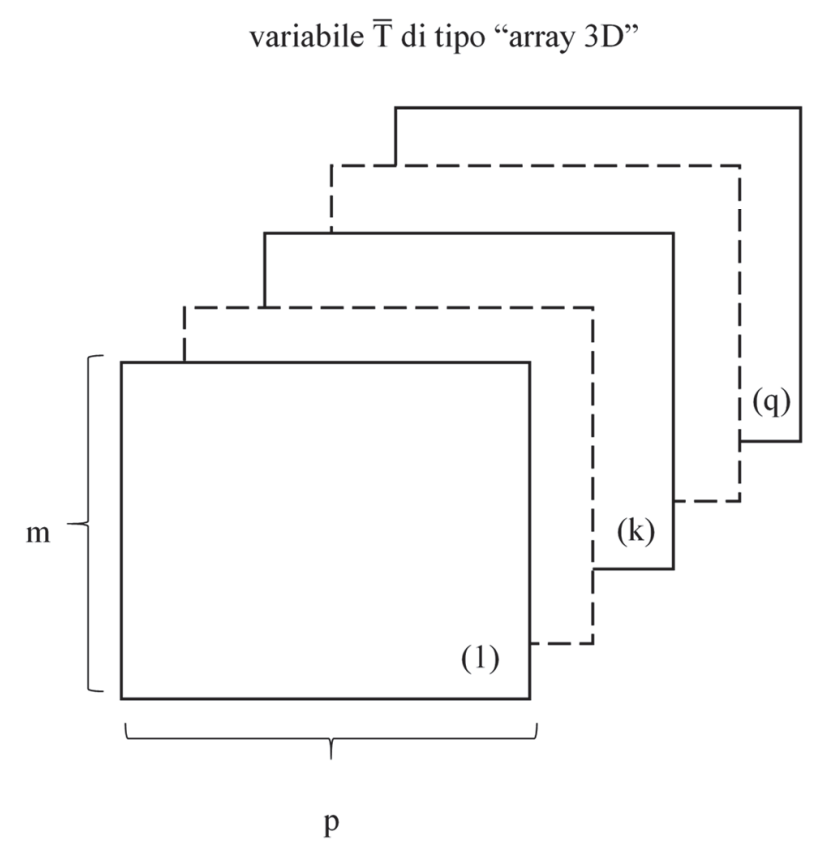

b)

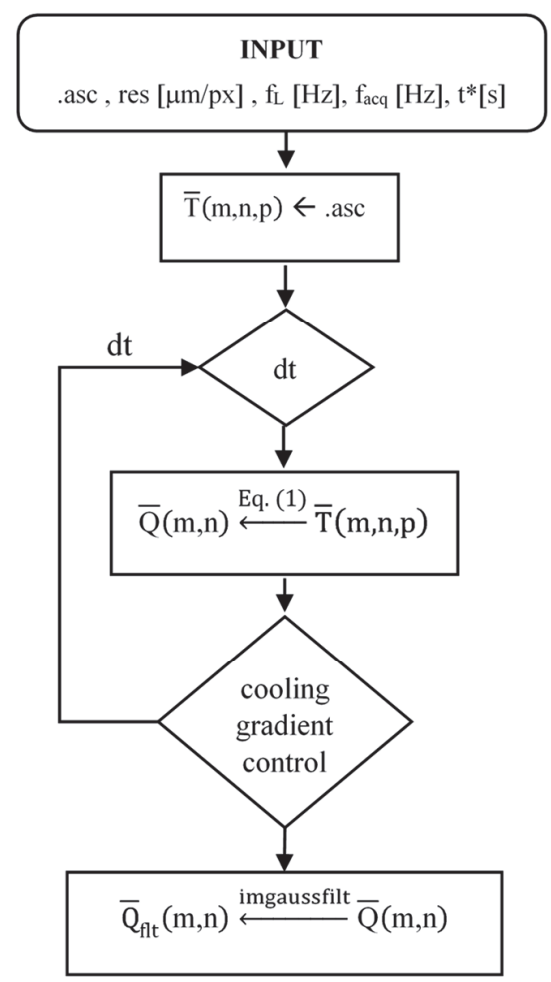

Figure 4: Schematic representation of the 3-dimensional array $\bar{T}$ (a). Flowchart of the data analysis to obtain the energy distribution at the notch tip. (b)

In order to obtain the energy distribution at the notch tip of the considered specimens, a numerical procedure was developed by using the Matlab code. First, the Altair video recording file (*.ptw) was converted into an ASCII film file (*.asc), which is readable in Matlab. Next, the ASCII file was input to a dedicated Matlab script, that converts it into a Matlab 3-dimensional array, named $\bar{T}(m, n, p)$, having dimension $\mathrm{m}$-by-n-by-p. The $\mathrm{m}, \mathrm{n}$ values are the dimensions of the frame expressed in terms of pixels, reduced to avoid vignetting ( $\mathrm{m}=136 \mathrm{px}, \mathrm{n}=167 \mathrm{px}$ ), and $\mathrm{p}$ is the number of frames acquired by the infrared camera (i.e $\mathrm{p}$ is equal to 2000). A schematic illustration of $\bar{T}(m, n, p)$ is shown in Fig. 4a. Let $\mathrm{i}, \mathrm{j}$ and $\mathrm{k}$ be the indexes of $\bar{T}(m, n, p)$. An element of this $3 \mathrm{D}$ array corresponds to a temperature value of the $\mathrm{n}$-th pixel having coordinate $\mathrm{i}$ and $\mathrm{j}$ for the $\mathrm{k}$-th frame. In this way, fixing $\mathrm{i}$ and $\mathrm{j}$ and plotting $\mathrm{T}_{\mathrm{ij}}$ against the time (obtained from the division of the $\mathrm{k}$ index value by $\mathrm{f}_{\text {acq }}$ ), the time variant temperature graph, commonly used for evaluated the $\mathrm{Q}$ parameter, is obtained for the $\mathrm{n}$-th pixel. A tentative value of $0.1 \mathrm{~s}$ was assigned to a numerical variable, named "dt", for evaluating the cooling gradient of the n-th pixel and it was kept constant for all pixels (see Fig. 4b). In practice, the numerical evaluation of the cooling gradient was performed by the polyfit matlab function, which returns the value of the slope of the linear fitting of the data within the time window "dt". Finally, $\mathrm{Q}_{\mathrm{ij}}$ is evaluated applying Eqn. (1). This operation was routinely performed for all pixels by a for loop, resulting in a m-by-n matrix composed by $\mathrm{Q}_{\mathrm{ij}}$ values, called $\bar{Q}(m, n)$. Since the same $\mathrm{dt}$ value was fixed for all the pixels and a certain level of noise in the measurements was present, the cooling gradient might result meaningless for some pixels. Therefore, after plotting the $\bar{Q}(m, n)$ matrix, a check was performed to single-out unrealistic spike-like values.

Then, the $\mathrm{dt}$ value was iteratively modified in the range from $0.05 \mathrm{~s}$ to $0.15 \mathrm{~s}$ in order to eliminate the aforementioned unrealistic $\mathrm{Q}_{\mathrm{ij}}$ values. Once passed this control, the last step consisted in filtering the $\bar{Q}(m, n)$ matrix, adopting the "imgaussfilt" matlab function, which uses a Gaussian smoothing kernel with specified standard deviation. For this application, a standard deviation ranging from 4 to 6 was adopted, by obtaining the $\bar{Q}_{f t t}(m, n)$ matrix. 
a) $r_{n}=3 \mathrm{~mm}, \sigma_{a n}=190 \mathrm{MPa}, \mathrm{f}_{\mathrm{L}}=10 \mathrm{~Hz}$

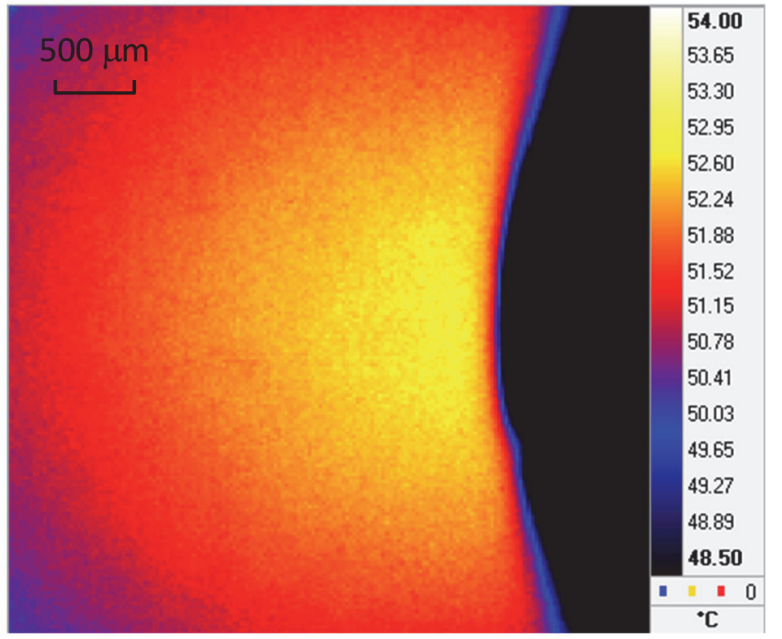

c) $r_{\mathrm{n}}=1 \mathrm{~mm}, \sigma_{\mathrm{an}}=150 \mathrm{MPa}, \mathrm{f}_{\mathrm{L}}=10 \mathrm{~Hz}$

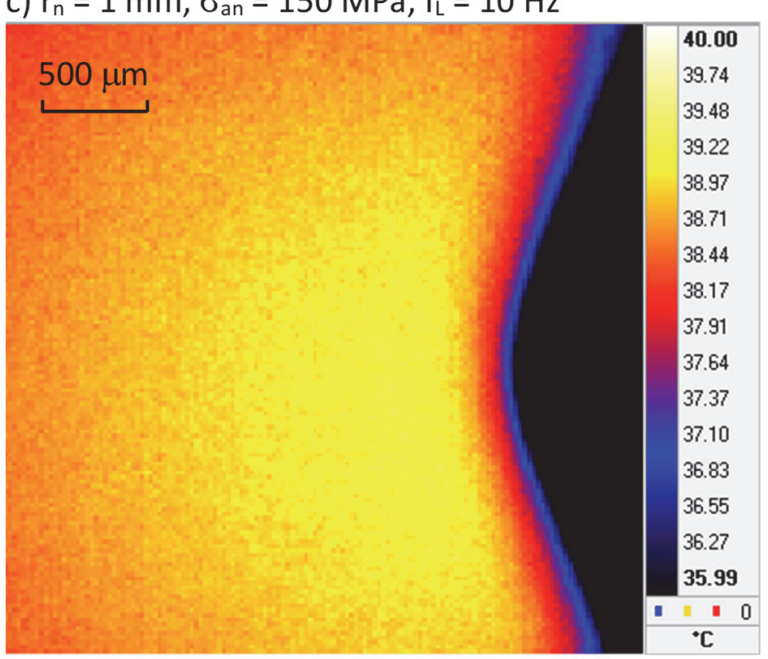

e) $r_{n}=0.5 \mathrm{~mm}, \sigma_{a n}=190 \mathrm{MPa}, \mathrm{f}_{\mathrm{L}}=5 \mathrm{~Hz}$

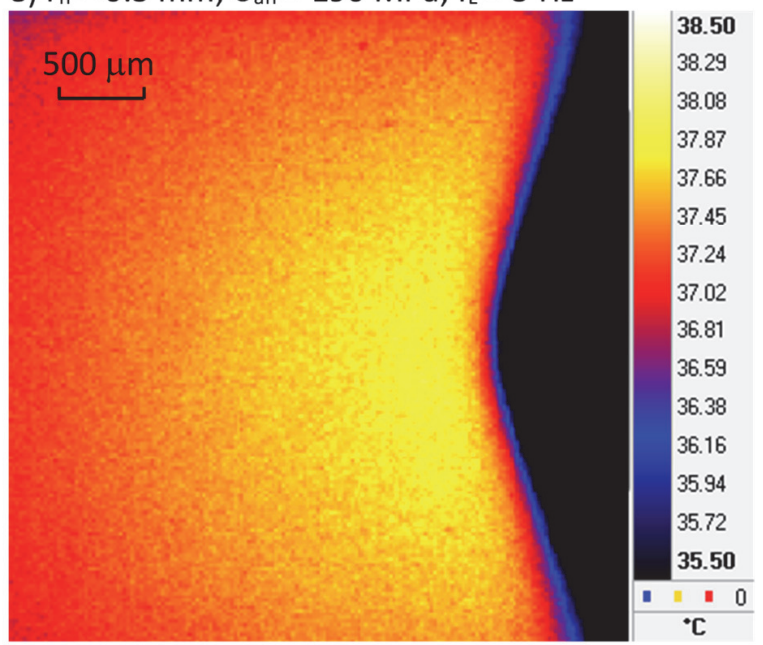

b) $r_{n}=3 \mathrm{~mm}, \sigma_{a n}=110 \mathrm{MPa}, \mathrm{f}_{\mathrm{L}}=25 \mathrm{~Hz}$

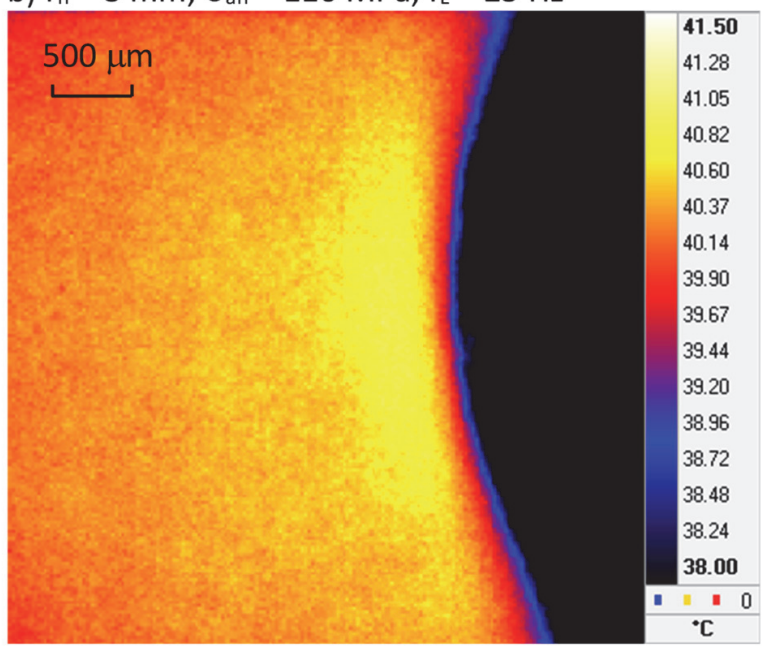

d) $r_{\mathrm{n}}=1 \mathrm{~mm}, \sigma_{\mathrm{an}}=120 \mathrm{MPa}, \mathrm{f}_{\mathrm{L}}=15 \mathrm{~Hz}$

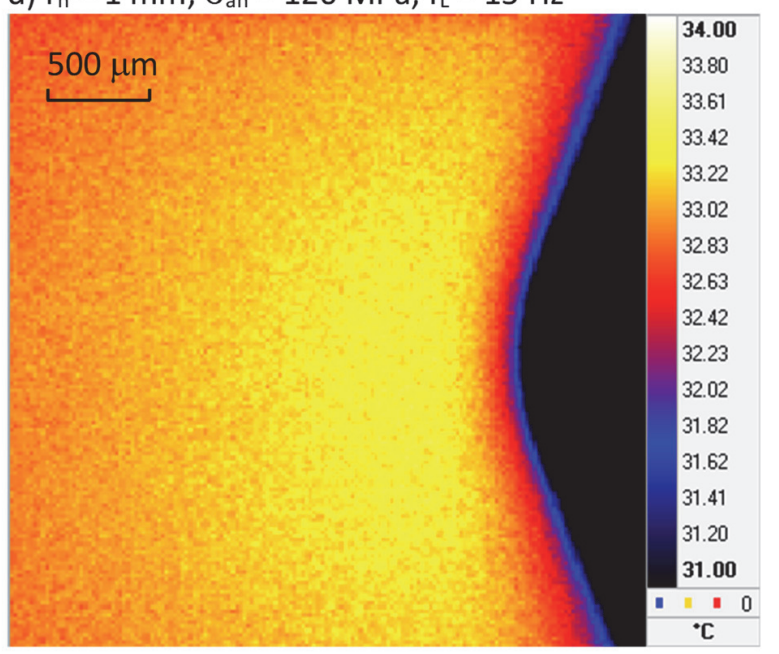

f) $r_{n}=0.5 \mathrm{~mm}, \sigma_{a n}=100 \mathrm{MPa}, \mathrm{f}_{\mathrm{L}}=35 \mathrm{~Hz}$

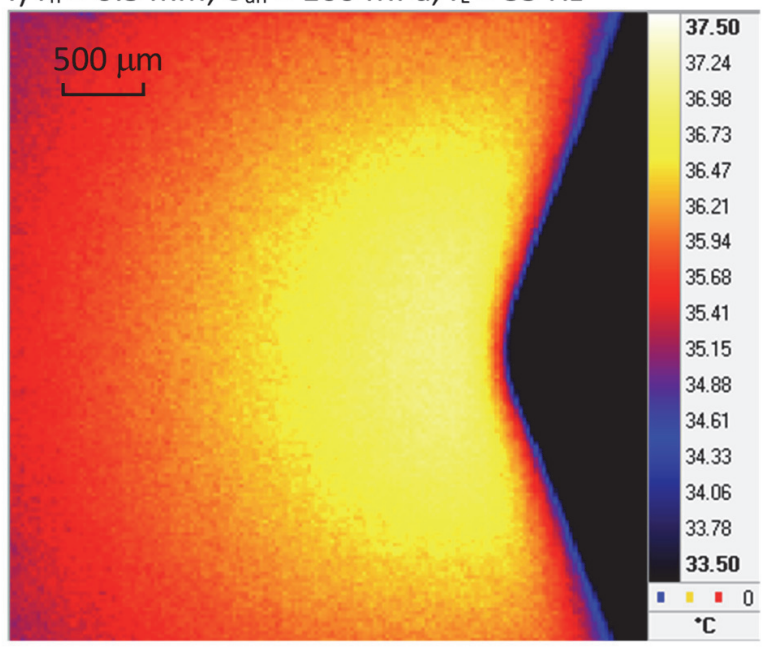

Figure 5: Temperature maps observed during the fatigue tests. 

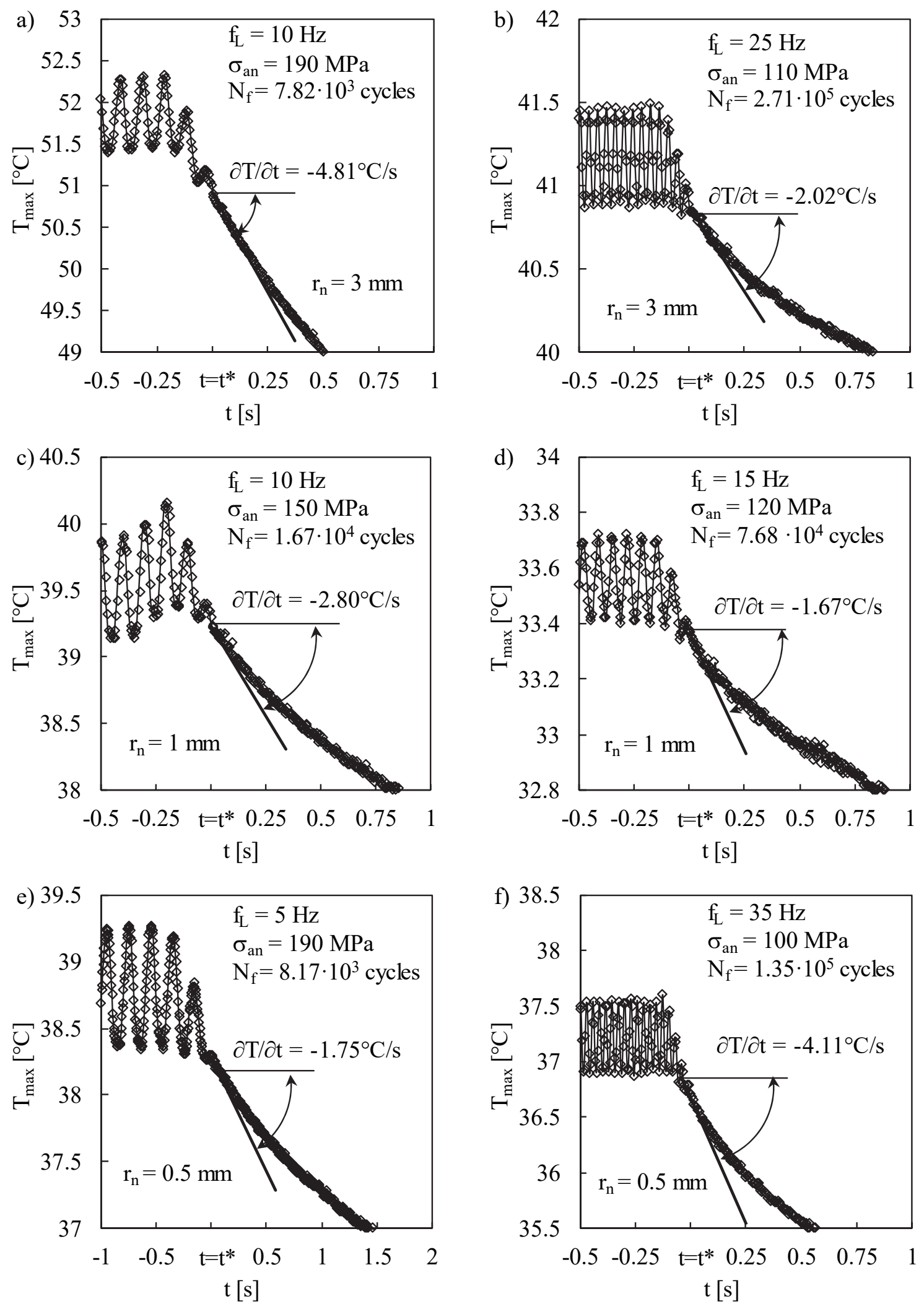

Figure 6: Heat energy distributions at the notch tip: $(a, b,) r_{n}=3 \mathrm{~mm}, \sigma_{a n}=170 \mathrm{MPa}, \mathrm{N}_{\mathrm{f}}=1.85 \cdot 10^{4}$ cycles; (c,d) $\mathrm{r}_{\mathrm{n}}=1 \mathrm{~mm}, \sigma_{\mathrm{an}}=150 \mathrm{MPa}$, $\mathrm{N}_{\mathrm{f}}=1.67 \cdot 10^{4}$ cycles; (e,f) $\mathrm{r}_{\mathrm{n}}=0.5 \mathrm{~mm}, \sigma_{\mathrm{an}}=100 \mathrm{MPa}, \mathrm{N}_{\mathrm{f}}=1.35 \cdot 10^{5}$ cycles 
It is well known that there is a certain level of uncertainty in detecting the edges of a body, by using thermography. Therefore, a gentle scratch was made on the painted surface of the specimens. Before each fatigue test, the distance of this scratch from the notch tip was measured by using the digital microscope, in order to define the position of the notch tip ( $\mathrm{x}=0$ and $y=0)$ in the thermal image as well as to calculate the actual geometrical resolution ( $\mu \mathrm{m} / \mathrm{pixels})$ of each experimental test.

The geometrical resolution was stored in a variable called "res" (see Fig.4b). Having "res", a grid of metric coordinates was created by using the meshgrid matlab function, allowing to plot the energy distribution with a metric coordinate system centered at the notch tip. Furthermore, in order to exclude the notch's edges from the final results, the negative portion of images was removed $(\mathrm{x}<0)$. In summary, all phases which were followed to compute the heat energy distribution are synthesised in Fig. 4b.

a)

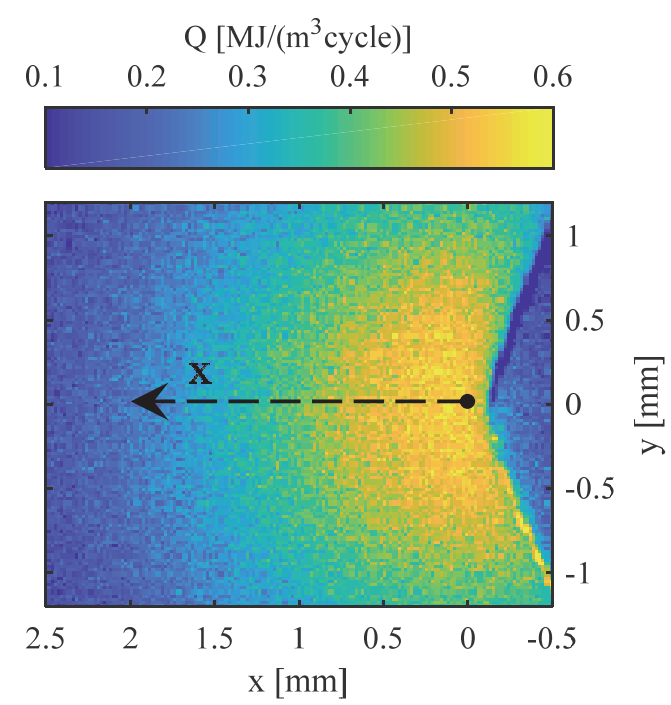

c)

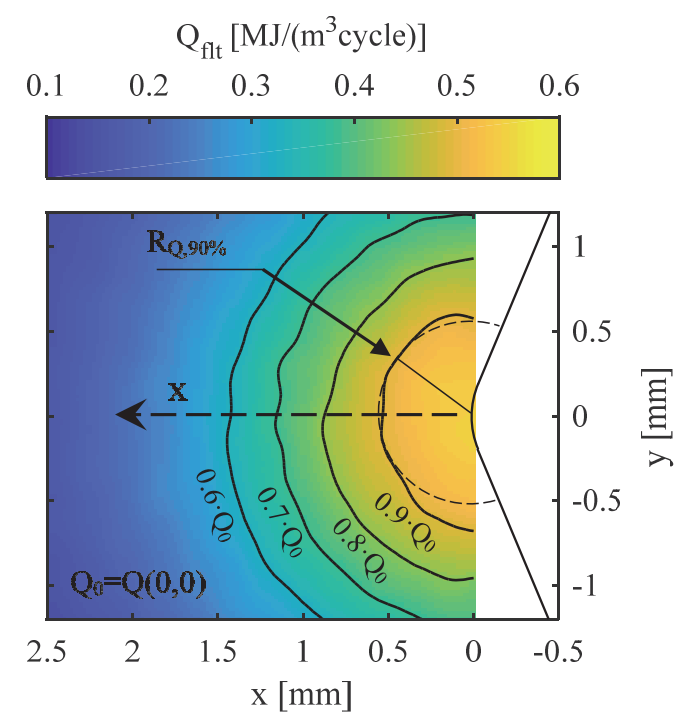

b)

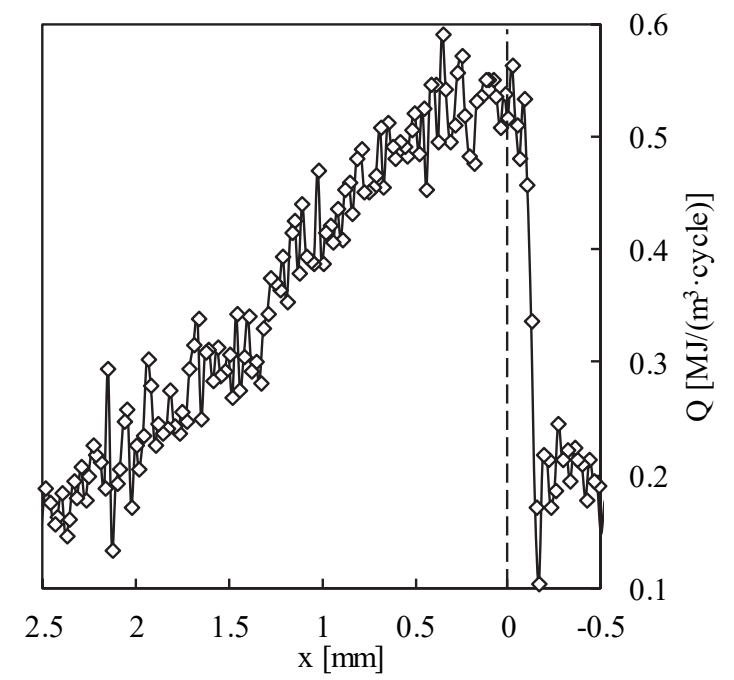

d)

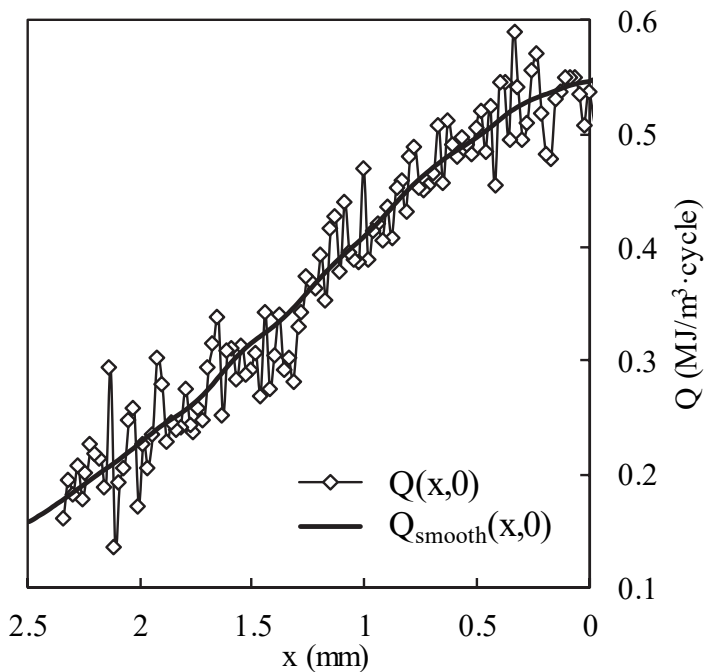

Figure 7: Example of raw data of the energy distribution $\mathrm{Q}(\mathrm{x}, \mathrm{y})$ (a) and along the coordinate $\mathrm{y}=0$ (along the notch bisector (b). The filtered energy distribution $\mathrm{Q}_{\mathrm{flt}}(\mathrm{x}, \mathrm{y})(\mathrm{c})$ and the relevant distribution along the notch bisector $(\mathrm{y}=0)(\mathrm{d})$. ( $\mathrm{a}$-d) data are referred to the acquisition obtained at $\mathrm{N}=8.12 \cdot 10^{3}$ cycles of the specimen characterised by $\mathrm{r}_{\mathrm{n}}=0.5 \mathrm{~mm}, \sigma_{\mathrm{an}}=130 \mathrm{MPa}$, and $\mathrm{N}_{\mathrm{f}}=6.76 \cdot 10^{4}$. 
a) $r_{\mathrm{n}}=3 \mathrm{~mm}, \sigma_{\text {an }}=190 \mathrm{MPa}, \mathrm{N} / \mathrm{N}_{\mathrm{f}}=0.24, \mathrm{~N}_{\mathrm{f}}=7.82 \cdot 10^{3}$ cycles $\mathrm{Q}_{0}=1.98\left[\mathrm{MJ} / \mathrm{m}^{3}\right.$ cycle $], \mathrm{f}_{\mathrm{L}}=10 \mathrm{~Hz}$

$\mathrm{Q}_{\mathrm{ftt}}\left[\mathrm{MJ} / \mathrm{m}^{3} \mathrm{cycle}\right]$

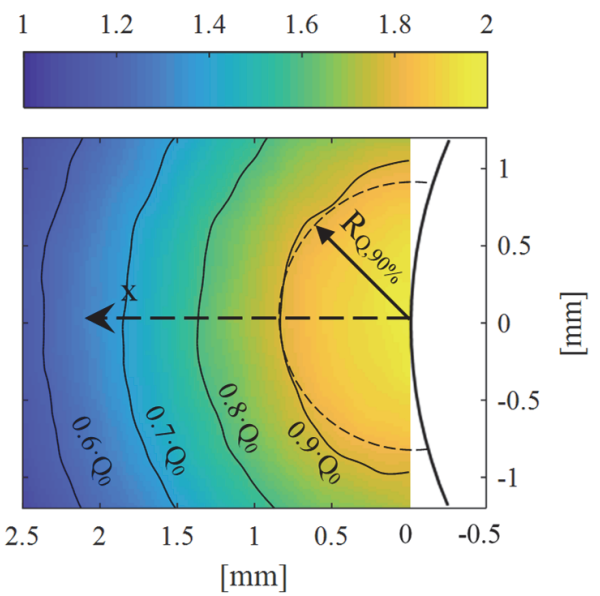

c) $r_{\mathrm{n}}=1 \mathrm{~mm}, \sigma_{\mathrm{an}}=150 \mathrm{MPa}, \mathrm{N} / \mathrm{N}_{\mathrm{f}}=0.28, \mathrm{~N}_{\mathrm{f}}=1.67 \cdot 10^{4}$ cycles, $\mathrm{Q}_{0}=1.17\left[\mathrm{MJ} / \mathrm{m}^{3}\right.$ cycle], $\mathrm{f}_{\mathrm{L}}=10 \mathrm{~Hz}$

$\mathrm{Q}_{\mathrm{ftt}}\left[\mathrm{MJ} / \mathrm{m}^{3} \mathrm{cycle}\right]$

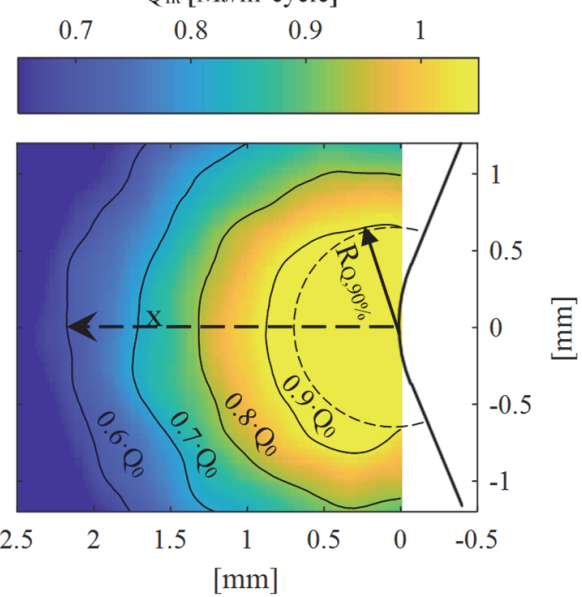

e) $r_{n}=0.5 \mathrm{~mm}, \sigma_{\text {an }}=190 \mathrm{MPa}, \mathrm{N} / \mathrm{N}_{\mathrm{f}}=0.21, \mathrm{~N}_{\mathrm{f}}=8.17 \cdot 10^{3}$ cycles, $\mathrm{Q}_{0}=1.77\left[\mathrm{MJ} / \mathrm{m}^{3}\right.$ cycle $], \mathrm{f}_{\mathrm{L}}=5 \mathrm{~Hz}$

$$
\mathrm{Q}_{\text {fit }}\left[\mathrm{MJ} / \mathrm{m}^{3} \mathrm{cycle}\right]
$$
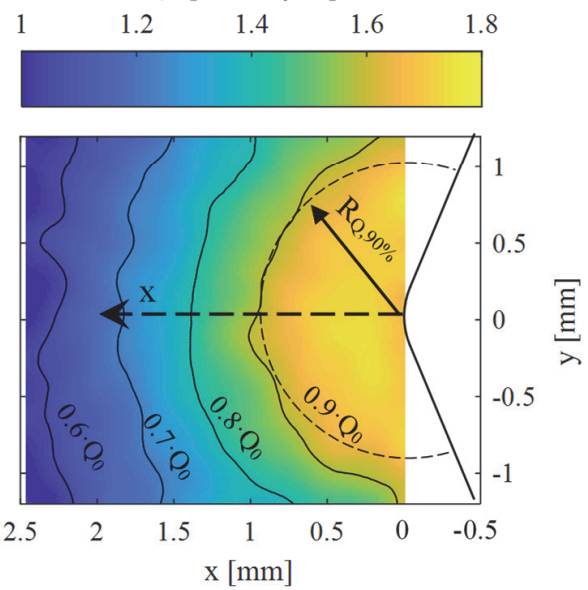

b) $\mathrm{r}_{\mathrm{n}}=3 \mathrm{~mm}, \sigma_{\mathrm{an}}=110 \mathrm{MPa}, \mathrm{N} / \mathrm{N}_{\mathrm{f}}=0.42, \mathrm{~N}_{\mathrm{f}}=2.71 \cdot 10^{5}$ cycles, $\mathrm{Q}_{0}=0.38\left[\mathrm{MJ} / \mathrm{m}^{3}\right.$ cycle $], \mathrm{f}_{\mathrm{L}}=25 \mathrm{~Hz}$

Qfft $\left[\mathrm{MJ} / \mathrm{m}^{3} \mathrm{cycle}\right]$

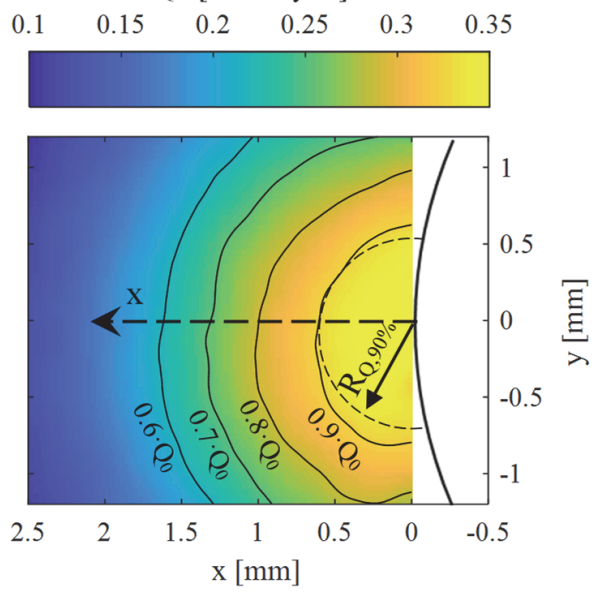

d) $\mathrm{r}_{\mathrm{n}}=1 \mathrm{~mm}, \sigma_{\text {an }}=120 \mathrm{MPa}, \mathrm{N} / \mathrm{N}_{\mathrm{f}}=0.13, \mathrm{~N}_{\mathrm{f}}=7.68 \cdot 10^{4}$ cycles, $\mathrm{Q}_{0}=0.42\left[\mathrm{MJ} / \mathrm{m}^{3}\right.$ cycle $], \mathrm{f}_{\mathrm{L}}=15 \mathrm{~Hz}$

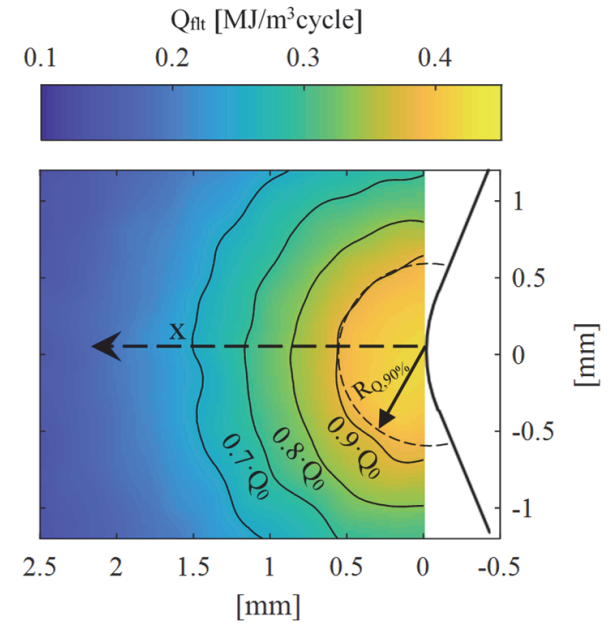

f) $\mathrm{r}_{\mathrm{n}}=0.5 \mathrm{~mm}, \sigma_{\mathrm{an}}=100 \mathrm{MPa}, \mathrm{N} / \mathrm{N}_{\mathrm{f}}=0.08, \mathrm{~N}_{\mathrm{f}}=1.35 \cdot 10^{5}$ cycles, $\mathrm{Q}_{0}=0.51\left[\mathrm{MJ} / \mathrm{m}^{3}\right.$ cycle $], \mathrm{f}_{\mathrm{L}}=35 \mathrm{~Hz}$

Qfit $\left[\mathrm{MJ} / \mathrm{m}^{3}\right.$ cycle $]$
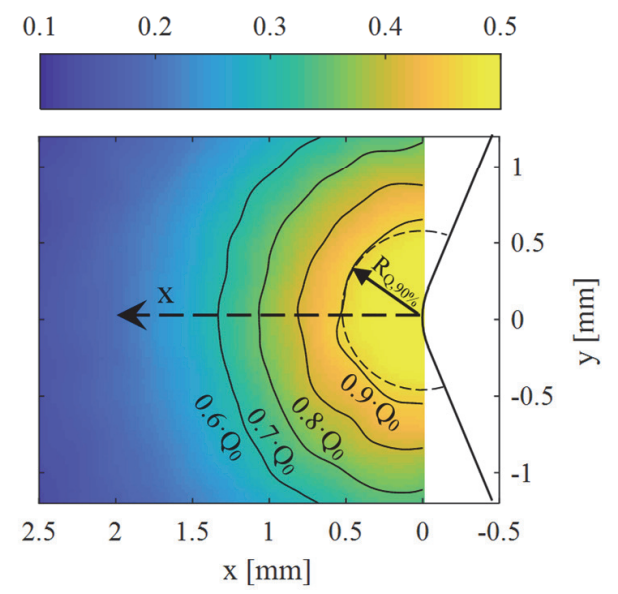

Figure 8: Heat energy distributions at the notch tip: $(a, b,) r_{n}=3 \mathrm{~mm}, \sigma_{a n}=170 \mathrm{MPa}, \mathrm{N}_{\mathrm{f}}=1.85 \cdot 10^{4}$ cycles; (c,d) $\mathrm{r}_{\mathrm{n}}=1 \mathrm{~mm}, \sigma_{\mathrm{an}}=150 \mathrm{MPa}$, $\mathrm{N}_{\mathrm{f}}=1.67 \cdot 10^{4}$ cycles; (e,f) $\mathrm{r}_{\mathrm{n}}=0.5 \mathrm{~mm}, \sigma_{\mathrm{an}}=100 \mathrm{MPa}, \mathrm{N}_{\mathrm{f}}=1.35 \cdot 10^{5}$ cycles 


\section{RESULTS}

$\mathrm{F}$

at the notch tip

ig. 5 shows typical temperature maps registered at the notch tip at time $\mathrm{t}=\mathrm{t}^{*}$, for different notch radii and applied nominal stress amplitude, $\sigma_{a n}$. As it can be expected, the maximum temperature level was reached in the case of the highest applied $\sigma_{\mathrm{an}}$ and the greatest notch radius, since the heat generation involves a certain volume of material embracing the notch tip. Fig. 6a-f shows the temperature versus time acquisitions relevant to Fig. 6a-f, respectively. In particular, Fig. 6 reports the maximum temperature $T_{\max }$ extracted frame-by-frame: it was found that essentially $T_{\max }$ is the temperature at the notch tip and that for the notch tip radii analysed in this paper, the time window considered to calculate the cooling gradient is of the order of one tenth of a second and the corresponding temperature decrease is of the order of some tenths of a degree.

Fig. 7a shows, as an example, the $\mathrm{Q}(\mathrm{x}, \mathrm{y})$ raw data measured at $\mathrm{N}=8.12 \cdot 10^{3}$ cycles for a specimen having $\mathrm{r}_{\mathrm{n}}=0.5 \mathrm{~mm}$ and subjected to $\sigma_{a n}=130 \mathrm{MPa}\left(\mathrm{N}_{\mathrm{f}}=6.76 \cdot 10^{4}\right.$ cycles), whereas the distribution $\mathrm{Q}(\mathrm{x}, 0)$ along the notch bisector is reported in Fig. 7b. As stated above, the results are affected by a certain level of noise because the dt variable was maintained constant for all the pixels of the thermal images. The relevant filtered results, $\mathrm{Q}_{\mathrm{ft}}(\mathrm{x}, \mathrm{y})$, are shown in Fig. 7c, while Fig. 7d reports the comparison between $\mathrm{Q}(\mathrm{x}, 0)$ and $\mathrm{Q}_{\mathrm{ft}}(\mathrm{x}, 0)$ along the notch bisector is reported.

Let us define $\mathrm{Q}_{0}$ the energy dissipated at the notch tip (i.e $\mathrm{Q}_{\mathrm{ftt}}(0,0)$ ). Fig. 7c shows the constant energy contours normalized with respect to $\mathrm{Q}_{0}$. It is worth noting that in Fig. 7c the iso-energy contours seem to be circular and centered at the not tip. In particular, a circular contour with radius $\mathrm{R}_{\mathrm{Q}, 90 \%}$ has been plotted in order to identify the biggest region where the energy calculated is equal or greater than $90 \%$ of $\mathrm{Q}_{0}$. For the example reported in Fig. $7 \mathrm{c} \mathrm{R}_{\mathrm{Q}, 90 \%}$ is equal to $0.54 \mathrm{~mm}$.

Fig. 8 shows more examples of energy distribution $\mathrm{Q}(\mathrm{x}, \mathrm{y})$ and the relevant distribution along the notch bisector $\mathrm{Q}(\mathrm{x}, 0)$, for different notch tip radii and applied stress amplitudes. The evaluation of the $\mathrm{R}_{\mathrm{Q}, 90 \%}$ has been carried out on selected specimens and the results are summarized in Tab. 1. Although the estimates of $\mathrm{R}_{\mathrm{Q}, 90 \%}$ ranges from 0.53 to $0.87 \mathrm{~mm}$, there may be a link between $\mathrm{R}_{\mathrm{Q}, 90 \%}$ and the structural volume size for fatigue strength assessment evaluated in a recent work $[21,23]$ for the same material and testing condition, but more investigation should be carried out.

\begin{tabular}{llllllll}
\hline $\begin{array}{l}\mathrm{r}_{\mathrm{n}} \\
{[\mathrm{mm}]}\end{array}$ & $\begin{array}{l}\sigma_{\mathrm{an}} \\
{[\mathrm{MPa}]}\end{array}$ & $\begin{array}{l}\mathrm{f}_{\mathrm{L}} \\
{[\mathrm{Hz}]}\end{array}$ & $\mathrm{N}_{\mathrm{f}}$ & $\mathrm{N}^{*} / \mathrm{N}_{\mathrm{f}}$ & $\begin{array}{l}\mathrm{Q}_{0} \\
{\left[\mathrm{MJ} /\left(\mathrm{m}^{3} \mathrm{cycle}\right)\right]}\end{array}$ & $\begin{array}{l}\mathrm{R}_{\mathrm{Q}, 9 \%} \\
{[\mathrm{~mm}]}\end{array}$ & $\mathrm{N} / \mathrm{Nf}$ \\
3 & 190 & 10 & $7.82 \cdot 10^{3}$ & 0.41 & 1.98 & 0.85 & 0.24 \\
3 & 170 & 10 & $1.85 \cdot 10^{4}$ & 0.61 & 1.45 & 0.87 & 0.42 \\
3 & 110 & 25 & $2.71 \cdot 10^{5}$ & 0.67 & 0.38 & 0.55 & 0.17 \\
1 & 150 & 10 & $1.67 \cdot 10^{4}$ & 0.33 & 1.17 & 0.64 & 0.28 \\
1 & 120 & 15 & $7.68 \cdot 10^{4}$ & 0.40 & 0.42 & 0.55 & 0.13 \\
0.5 & 190 & 5 & $8.17 \cdot 10^{3}$ & 0.40 & 1.77 & 0.83 & 0.21 \\
0.5 & 100 & 35 & $1.35 \cdot 10^{5}$ & 0.13 & 0.51 & 0.53 & 0.08 \\
0.5 & 130 & 25 & $6.76 \cdot 10^{4}$ & 0.22 & 0.55 & 0.54 & 0.12 \\
\hline
\end{tabular}

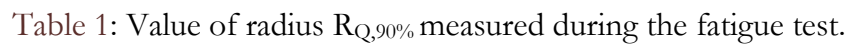

\section{Analysis of the heat generation area}

At an arbitrary point of a material subjected to cyclic stresses, the first law of thermodynamic in terms of a mean power exchanged over one cycle can be written as follow:

$$
\left(\oint \sigma_{i j} \cdot \varepsilon_{i j}\right) \cdot f_{L}=H+\rho \cdot c \cdot \frac{\partial T_{m}(t)}{\partial t}+\dot{E}_{p}
$$

where $H=Q \cdot f_{L}$ is the thermal power dissipated by conduction, convention and radiation, $T_{m}(t)$ is the mean temperature of the alternating thermoelastic effect and $\dot{\mathrm{E}}_{\mathrm{p}}$ is the rate of accumulation of damaging energy in a unit of volume. When $\mathrm{T}_{\mathrm{m}}(\mathrm{t})$ reaches a constant value Eqn. (2) can be rewritten as follows: 
$\left(\oint \sigma_{i j} \cdot \varepsilon_{i j}\right) \cdot f_{L}=H+\dot{E}_{p}$

a)

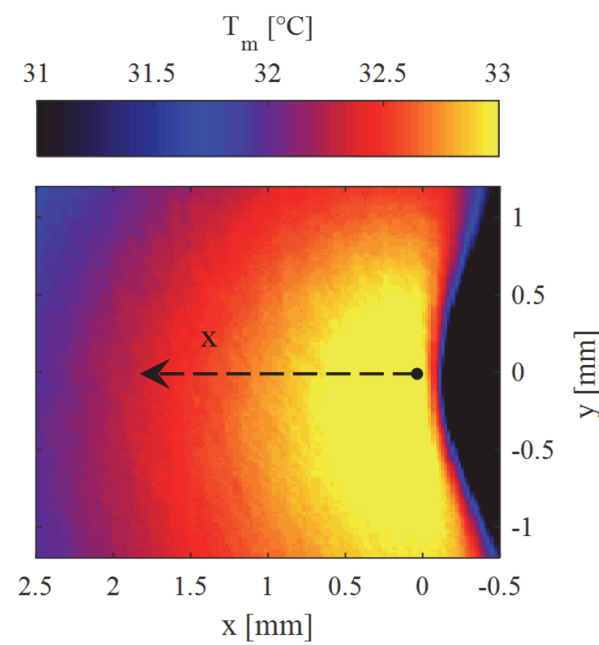

c)
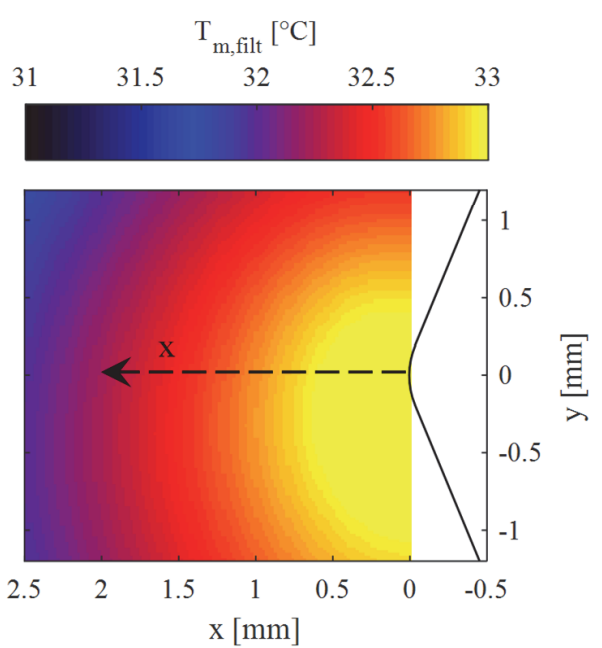

b)

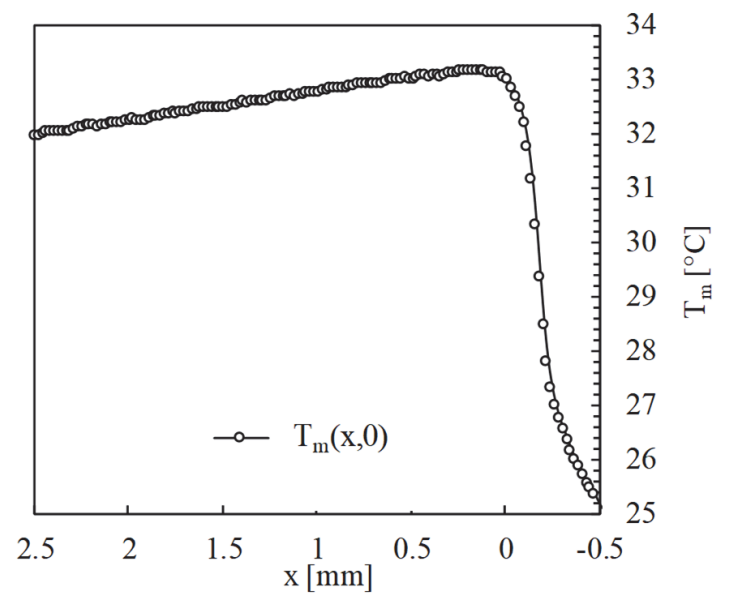

d)

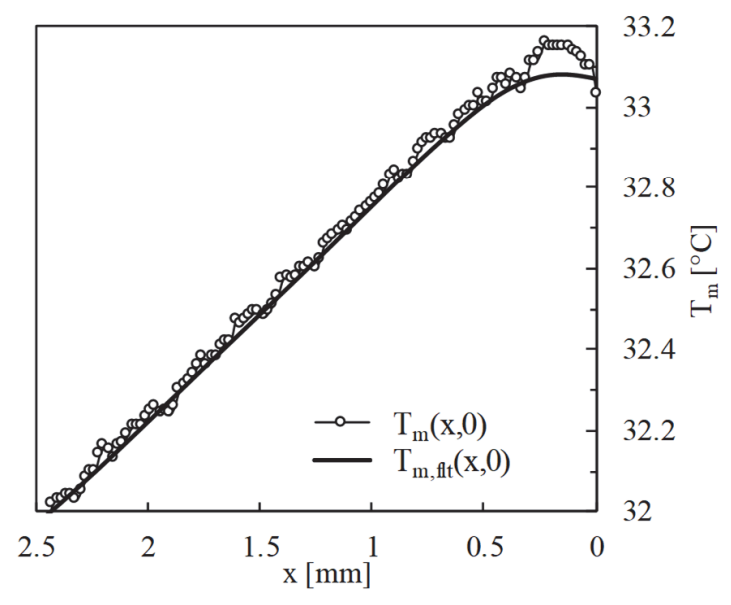

Figure 9: Steady-state temperature $\left(\mathrm{T}_{\mathrm{m}}(\mathrm{x}, \mathrm{y})\right)$ field (a) and distribution along the notch bisector $(\mathrm{y}=0)(\mathrm{b})$. Filtered steady-state temperature $\left(\mathrm{T}_{\mathrm{m}, \text { filt }}(\mathrm{x}, \mathrm{y})\right)$ field $(\mathrm{c})$ and the relevant distribution along the notch bisector $(\mathrm{y}=0)(\mathrm{d})$. The relevant fatigue test details are reported in Fig. 7.

In [14], it was demonstrated that the contributions of Q due to convection and radiation can be neglected with respect the conduction, therefore a temperature field developed by thermal power generation can be described by the Fourier's equation:

$$
\rho \cdot c \cdot \frac{\partial T_{m}(t)}{\partial t}=H+\lambda \cdot \nabla^{2} T
$$

After stabilization of $\mathrm{T}_{\mathrm{m}}$, in absence of thermal power generation, the equation of the temperature field in a steady-state condition becomes:

$$
\lambda \cdot \nabla^{2} T=0
$$

whereas if heat generation exists, the temperature field is described by the following one: 


$$
H=-\lambda \cdot \nabla^{2} T
$$

In order to evaluate the portion of frame in which $\mathrm{H}$ is null, the example of Fig. (7) has been taken into account for the following analysis. Firstly, the frames of ten loading cycles between $t_{\mathrm{s}}$ and $\mathrm{t}^{*}$ (see fig. 3) were processed by using the FLIR MotionByInterpolation tool, that allows the relative motion between the fixed focal lens and the moving of the specimens to be compensated. After that, the time-dependent temperature was averaged pixel-by-pixel over 80 frames (10 loading cycles in this example) and the resulting steady-state temperature $\left(\mathrm{T}_{\mathrm{m}}\right)$ field and distribution along the notch bisector are shown in Fig. (9a) and (9b). Fig. (9c) shows the same the temperature field of Fig. (9a) after filtering by means of a Gaussian smoothing kernel with a standard deviation equal to 8 . The comparison between the $\mathrm{T}_{\mathrm{m}}$ and $\mathrm{T}_{\mathrm{m} \text {, filt }}$ profiles along the notch bisector is shown in Fig. (9d).

a)

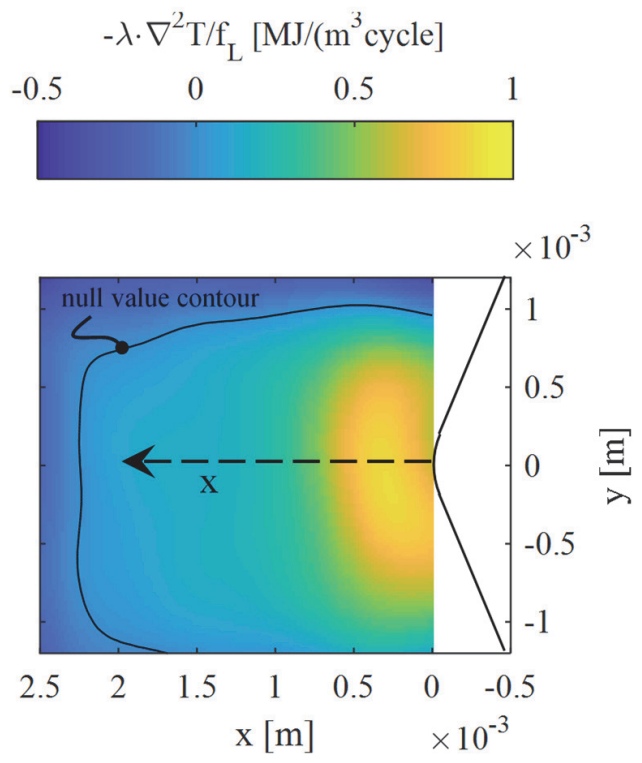

b)

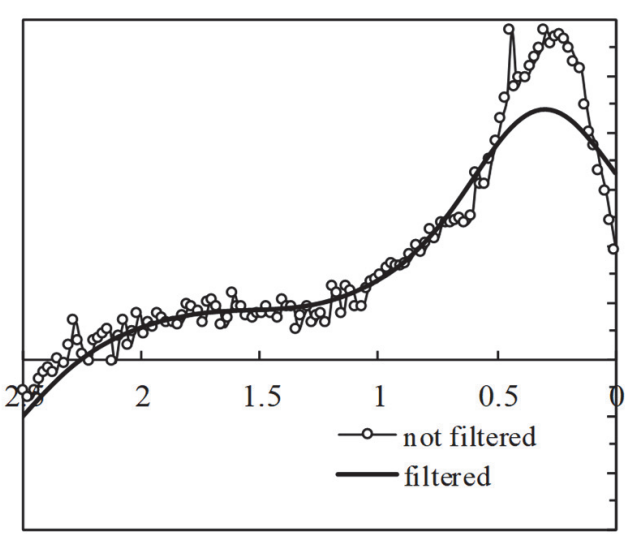

1.20

1.00

0.80

0.60

0.40

0.20

0.00

$-0.20 \stackrel{1}{\frac{1}{1}}$

$-0.40$

$-0.60$

$\mathrm{x}[\mathrm{mm}]$

Figure 10: Filtered Laplacian field (a) and comparison with the not filtered and the filtered Laplacian distributions along the notch bisector $(\mathrm{y}=0)(\mathrm{b})$.

Assuming that the temperature maps do not vary along the thickness of the specimen, the 2 dimensional Laplacian of $\mathrm{T}_{\mathrm{m} \text {,filt }}$ field was numerically calculated by using the Matlab function del2. Since the resulting distribution was affected by noise, the Laplacian field was filtered by using the same Gaussian filter used for $T_{m}$ map. Fig. (10a) reports the Laplacian field with sign reversed on which the contour related to the null value of the distribution is also plotted. The comparison between the raw and filtered Laplacian profiles along the notch bisector are shown in Fig. (10b). In Fig. (10a) it can be clearly seen that, inside of the contour, $\mathrm{H}$ is positive thus indicating the zone where heat generation exists.

\section{Finite element analysis}

A steady-state thermal finite element analysis was carried out for the fatigue test results of Fig (7) in order to verify the experimental temperature map of Fig. (9a), assigning a non-uniform specific heat power generation obtained from the

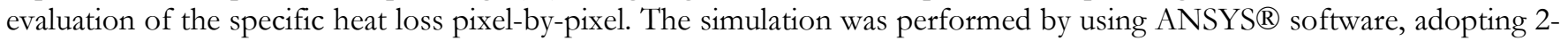
dimensional four node element PLANE55 of the Ansys' library. Isotropic thermal conductivity equal to $16 \mathrm{~W} /\left(\mathrm{m}{ }^{\circ} \mathrm{C}\right)$ was set as material property. A rectangular area having dimension equal to $2.5 \times 2.4 \mathrm{~mm}$ (the same dimension of the area analysed in Figs. (7) and (8)) was modelled and the element size was set equal to $21 \mu \mathrm{m}$ in order to obtain a mapped-mesh having a number of elements equal to the number of pixels of the temperature maps analysed in the previous section. Given the correspondence between element size and spatial resolution, it was possible to assign the specific heat generation rate, $\mathrm{H}=\mathrm{Q} \cdot \mathrm{f}_{\mathrm{L}}$, obtained from the pixel by pixel evaluation of $\mathrm{Q}$, in the region with $\mathrm{H}$ equal or greater than zero (the inner region of the black contour of Fig. (10a). The experimental temperature profiles of the borders of Fig. (9a) were assigned along the edges of the FE model, as thermal boundary conditions.

In Fig.(11a) the contour plot of the nodal temperature values is reported. For comparing the temperature map of Fig. (9a) and the numerical results of Fig. (11a), temperature distributions along three different paths indicated in Fig. (11a) have 
been reported in the Figs. (10b-d). The good correlation between the numerical and experimental data demonstrate that the distribution of Q around a notch tip can be captured with high level of accuracy, by using Eqn. (1) along with Eqn. (6).

a)

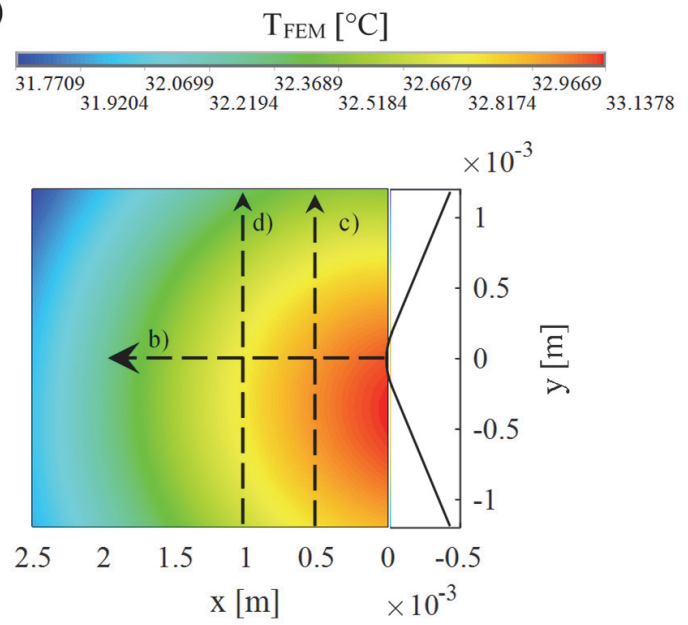

c)

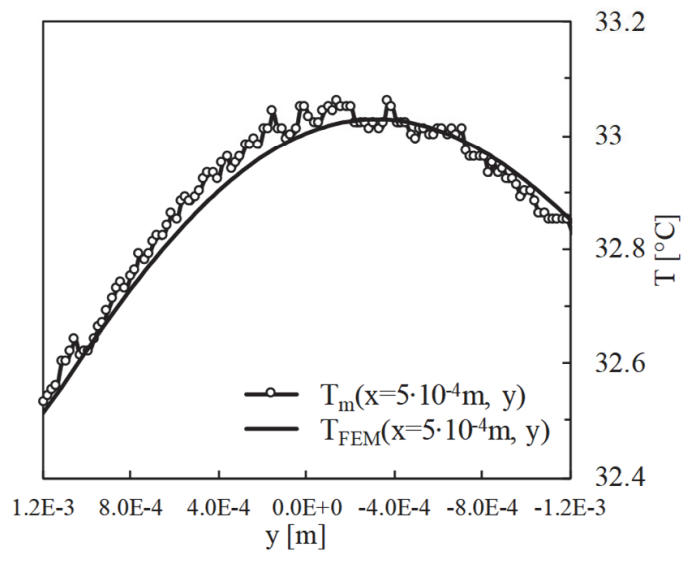

b)

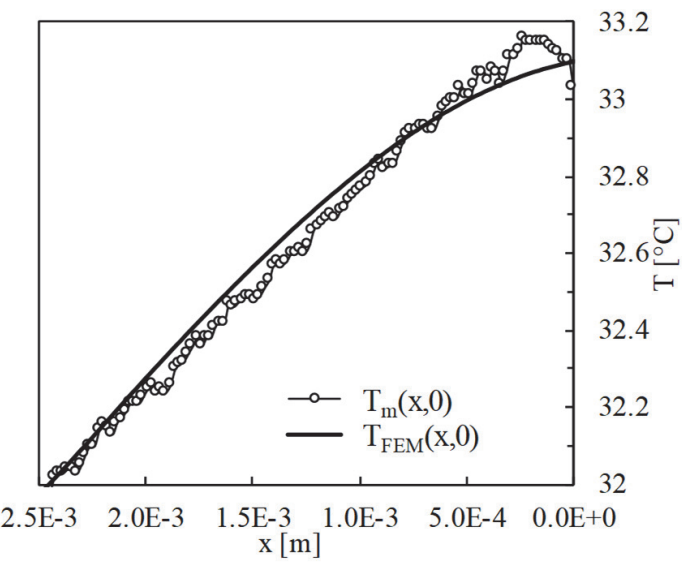

d)

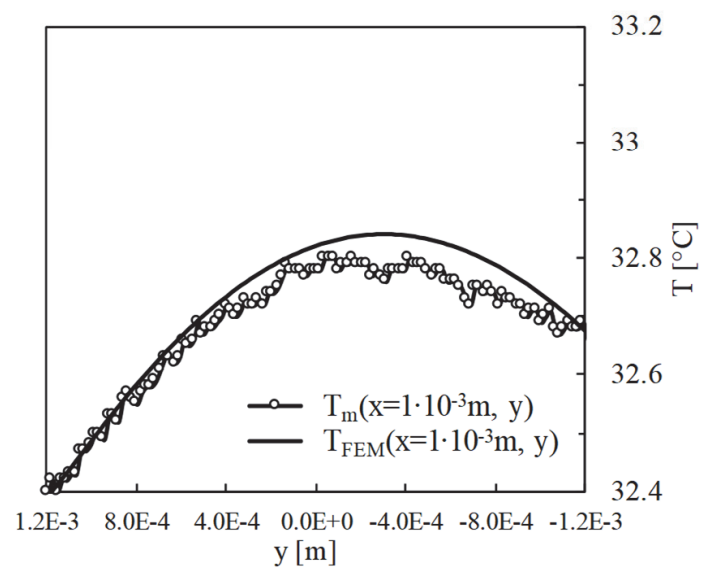

Figure 11: Contour plot of the nodal temperature solutions (a) and comparison between the experimental steady-state temperature and nodal solutions along three different path $(b, c, d)$.

\section{CONCLUSIONS}

I $\mathrm{n}$ the present contribution, an automated procedure is proposed to evaluate the distribution of the specific heat loss (Q parameter) around sharp V-notches, starting from the temperature maps captured around the tip of V notches, by using an infrared camera having a geometric resolution equal to $20 \mu \mathrm{m} /$ pixel. Fully reversed, constant amplitude fatigue tests were carried out on 4-mm-thick AISI 304L stainless steel specimens, having a lateral V-notch, with notch tip radii equal to 3,1 and $0.5 \mathrm{~mm}$ and opening angle of $135^{\circ}$.

The automated procedure was developed in Matlab ${ }^{\circledR}$ code taking the video recording file acquired by ALTAIR 5.90.002 commercial software as input file and computing Eq (1) pixel-by-pixel. Then $\mathrm{Q}$ distributions $(\mathrm{Q}(\mathrm{x}, \mathrm{y}))$ were analysed for a subset of specimens providing the circular region where the energy dissipated is equal or greater of $90 \%$ of the $Q$ value measured at the notch tip. The automated procedure was validated investigating the region in which heat power generation is developed due to dissipation of the plastic strain hysteresis energy as heat. In particular, the Laplacian distribution of the temperature map before the test stop was evaluated, in order to identify the region in which the heat power generation exists. Then, a 2D steady-state thermal finite element analysis was performed imposing the distribution of the heat power generation as thermal load and the experimental temperature measured along the edges of the temperature map as thermal boundary conditions. The results show a good correlation between numerical and experimental temperature data. Finally, 
by considering the material and the test conditions analysed in the present paper, it can be concluded that the distribution of the Q parameter can be considered practically constant, at least from an engineering point of view, within a circular region centered at the notch tip and having a radius ranging from 0.53 to $0.83 \mathrm{~mm}$.

\section{REFERENCES}

[1] Dengel, D., Harig, H. (1980). Estimation of the fatigue limit by progressively - incresing load tests, Fatigue Eng. Matérials Struct., 3, pp. 113-128.

[2] Luong, M.P. (1995). Infrared thermographic scanning of fatigue in metals, Nucl. Eng. Des., 158(2), pp. 363-376. DOI: 10.1016/0029-5493(95)01043-H.

[3] La Rosa, G., Risitano, A. (2000). Thermographic methodology for rapid determination of the fatigue limit of materials and mechanical components, Int. J. Fatigue, 22(1), pp. 65-73. DOI: 10.1016/S0142-1123(99)00088-2.

[4] Curà, F., Curti, G., Sesana, R. (2005). A new iteration method for the thermographic determination of fatigue limit in steels, Int. J. Fatigue, 27(4), pp. 453-459. DOI: 10.1016/j.ijfatigue.2003.12.009.

[5] Reifsnider, K.L., Williams, R.S. (1974). Determination of fatigue-related heat emission in composite materials, 14(12), pp. 479-485. DOI: 10.1007/BF02323148.

[6] Plekhov, O., Palin-Luc, T., Saintier, N., Uvarov, S., Naimark, O. (2005). Fatigue crack initiation and growth in a 35CrMo4 steel investigated by infrared thermography, Fatigue Fract. Eng. Mater. Struct. Fract. Eng. Mater. Struct., 28(1-2), pp. 169-178. DOI: 10.1111/j.1460-2695.2005.00856.x.

[7] Ummenhofer, T., Medgenberg, J. (2009). On the use of infrared thermography for the analysis of fatigue damage processes in welded joints, Int. J. Fatigue, 31(1), pp. 130-137. DOI: 10.1016/j.ijfatigue.2008.04.005.

[8] Jones, R., Krishnapillai, M., Cairns, K., Matthews, N. (2010). Application of infrared thermography to study crack growth and fatigue life extension procedures, Fatigue Fract. Eng. Mater. Struct., 33(12), pp. 871-884. DOI: $10.1111 /$ j.1460-2695.2010.01505.x.

[9] Fargione, G., Geraci, A., La Rosa, G., Risitano, A. (2002). Rapid determination of the fatigue curve by the thermographic method, Int. J. Fatigue, 24(1), pp. 11-9. DOI: 10.1016/S0142-1123(01)00107-4.

[10] Starke, P., Walther, F., Eifler, D. (2007). Fatigue assessment and fatigue life calculation of quenched and tempered SAE 4140 steel based on stress-strain hysteresis, temperature and electrical resistance measurements, Fatigue Fract. Eng. Mater. Struct., 30(11), pp. 1044-1051. DOI: 10.1111/j.1460-2695.2007.01174.x.

[11]Jegou, L., Marco, Y., Le Saux, V., Calloch, S. (2013). Fast prediction of the Wöhler curve from heat build-up measurements on Short Fiber Reinforced Plastic, Int. J. Fatigue, 47, pp. 259-267. DOI: 10.1016/j.ijfatigue.2012.09.007.

[12] Fan, J., Guo, X., Wu, C. (2012). A new application of the infrared thermography for fatigue evaluation and damage assessment, Int. J. Fatigue, 44, pp. 1-7. DOI: 10.1016/j.ijfatigue.2012.06.003.

[13] Risitano, A., Risitano, G. (2013). Cumulative damage evaluation in multiple cycle fatigue tests taking into account energy parameters, Int. J. Fatigue, 48, pp. 214-222. DOI: 10.1016/j.ijfatigue.2012.10.020.

[14] Meneghetti, G. (2007). Analysis of the fatigue strength of a stainless steel based on the energy dissipation, Int. J. Fatigue, 29(1), pp. 81-94. DOI: 10.1016/j.ijfatigue.2006.02.043.

[15] Ellyin, F. (1997). Fatigue damage, crack growth, and life prediction, Chapman \& Hall.

[16] Meneghetti, G., Ricotta, M., Atzori, B. (2013). A synthesis of the push-pull fatigue behaviour of plain and notched stainless steel specimens by using the specific heat loss, Fatigue Fract. Eng. Mater. Struct., 36(12), pp. 1306-1322. DOI: $10.1111 /$ ffe. 12071.

[17] Meneghetti, G., Ricotta, M. (2012). The use of the specific heat loss to analyse the low- and high-cycle fatigue behaviour of plain and notched specimens made of a stainless steel, Eng. Fract. Mech., 81, pp. 2-16. DOI: 10.1016/j.engfracmech.2011.06.010.

[18] Meneghetti, G., Ricotta, M., Negrisolo, L., Atzori, B. (2013). A Synthesis of the Fatigue Behavior of Stainless Steel Bars under Fully Reversed Axial or Torsion Loading by Using the Specific Heat Loss, Key Eng. Mater., 577-578, pp. 4536. DOI: 10.4028/www.scientific.net/KEM.577-578.453.

[19] Meneghetti, G., Ricotta, M., Atzori, B. (2016).The Heat Energy Dissipated in a Control Volume to Correlate the Fatigue Strength of Bluntly and Severely Notched Stainless Steel Specimens. Proceedings of the 21st European Conference on Fracture, ECF21. Catania, Italy, 2, pp. 2076-83.

[20] Meneghetti, G., Ricotta, M. (2016). Experimental estimation of the heat energy dissipated in a volume surrounding the tip of a fatigue crack, Fract. Struct. Integr., 0(35), pp. 172-181. DOI: 10.3221/IGF-ESIS.35.20.

[21] Meneghetti, G., Ricotta, M., Rigon, D. (2017). The heat energy dissipated in a control volume to correlate the fatigue 
strength of severely notched and cracked stainless steel specimens. Fatigue 2017, Cambridge, UK.

[22] Rigon, D., Ricotta, M., Meneghetti, G. (2017). An analysis of the specific heat loss at the tip of severely notched stainless steel specimens to correlate the fatigue strength, Theor. Appl. Fract. Mech., 92. DOI: 10.1016/j.tafmec.2017.09.003.

[23] Meneghetti, G., Ricotta, M. (2018). The heat energy dissipated in the material structural volume to correlate the fatigue crack growth rate in stainless steel specimens, Int. J. Fatigue, 115, 107-119. DOI: 10.1016/j.ijfatigue.2018.07.037. 